\title{
Parameters of Calcium Metabolism Fluctuated during Initiation or Changing of Antipsychotic Drugs
}

\author{
Dragan R. Milovanovic ${ }^{1}$, Marijana Stanojevic Pirkovic ${ }^{2}$, Snezana Zivancevic Simonovic ${ }^{3}$, \\ Milovan Matovic ${ }^{4}$, Slavica Djukic Dejanovic ${ }^{5}$, Slobodan M. Jankovic ${ }^{1}$, Dragan Ravanic ${ }^{5}$, \\ Milan Petronijevic ${ }^{6}$, Dragana Ignjatovic Ristic ${ }^{5}$, Violeta Mladenovic ${ }^{7}$, Mirjana Jovanovic ${ }^{5}$, \\ Sandra Nikolic Labovic ${ }^{5}$, Marina Pajovic ${ }^{5}$, Danijela Djokovic ${ }^{5}$, Dusan Petrovic ${ }^{5}$, and Vladimir Janjic ${ }^{5}$ \\ 'Department of Pharmacology, Toxicology and Clinical Pharmacology, Faculty of Medical Sciences University of Kragujevac, \\ Clinical Centre "Kragujevac", Kragujevac, Serbia \\ 2Department of Biochemistry, Faculty of Medical Sciences University of Kragujevac, Clinical Centre "Kragujevac", Kragujevac, Serbia \\ ${ }^{3}$ Department of Pathophysiology, Faculty of Medical Sciences University of Kragujevac, Clinical Centre "Kragujevac", Kragujevac, Serbia \\ ${ }^{4}$ Deparment of Nuclear Medicine, Faculty of Medical Sciences University of Kragujevac, Clinical Centre "Kragujevac", Kragujevac, Serbia \\ ${ }^{5}$ Clinic of Psychiatry, Faculty of Medical Sciences University of Kragujevac, Clinical Centre "Kragujevac", Kragujevac, Serbia \\ ${ }^{6}$ Clinic of Rheumatology, Military Medical Academy University of Defense, Belgrade, Serbia \\ ${ }^{7}$ Clinic of Internal Diseases, Faculty of Medical Sciences University of Kragujevac, Clinical Centre "Kragujevac", Kragujevac, Serbia
}

\begin{abstract}
Objective Serum parameters of calcium homeostasis were measured based on previously published evidence linking osteoporotic fractures and/or bone/mineral loss with antipsychotics.

Methods Prospective, four-week, time-series trial was conducted and study population consisted of patients of both genders, aged 3585 years, admitted within the routine practice, with acute psychotic symptoms, to whom an antipsychotic drug was either introduced or substituted. Serial measurements of serum calcium, phosphorous, magnesium, 25(OH)D, parathyroid hormone, calcitonin, osteocalcin and C-telopeptide were made from patient venous blood samples.

Results Calcium serum concentrations significantly decreased from baseline to the fourth week $(2.42 \pm 0.12 \mathrm{vs} .2 .33 \pm 0.16 \mathrm{mmol} / \mathrm{L}$, $\mathrm{p}=0.022, \mathrm{n}=25)$. The mean of all calcemia changes from the baseline was $-2.6 \pm 5.7 \%(-24.1$ to 7.7$)$ with more decreases than increases $(78$ vs. $49, \mathrm{p}=0.010)$ and more patents having negative sum of calcemia changes from baseline $(\mathrm{n}=28)$ than positive ones $(\mathrm{n}=10)(\mathrm{p}=0.004)$. There were simultaneous falls of calcium and magnesium from baseline $(63 / 15$ vs. $23 / 26, \mathrm{p}<0.001$; OR $=4.75,95 \%$ CI $2.14-10.51)$, phosphorous $(45 / 33$ vs. $9 / 40, \mathrm{p}<0.001 ; 6.06,2.59-14.20)$ and $25(\mathrm{OH}) \mathrm{D}$ concentrations $(57 / 21$ vs. $13 / 35, \mathrm{p}<0.001 ; 7.31,3.25-16.42)$, respectively. Calcemia positively correlated with magnesemia, phosphatemia and $25(\mathrm{OH}) \mathrm{D}$ values. Parathyroid hormone and C-telopeptide showed only subtle oscillations of their absolute concentrations or changes from baseline; calcitonin and osteocalcin did not change. Adjustment of final calcemia trend (depletion/accumulation) for relevant risk factors, generally, did not change the results.

Conclusion In patients with psychotic disorders and several risks for bone metabolism disturbances antipsychotic treatment was associated with the decrease of calcemia and changes in levels of the associated ions.

Psychiatry Investig 2016;13(1):89-101
\end{abstract}

Key Words Antipsychotic agents, Bone and bones, Calcium, Minerals, Blood chemical analysis.

\section{INTRODUCTION}

Two disorders which increase fracture risk, osteoporosis, a state of impaired bone quality and quantity, and osteomala-

Received: November 16, 2014 Revised: May 19, 2015 Accepted: May 29, 2015 Available online: October 14, 2015

$\triangle$ Correspondence: Dragan R. Milovanovic, MD, $\mathrm{PhD}$ Department of Pharmacology, Toxicology and Clinical Pharmacology, Faculty of Medical Sciences University of Kragujevac, Clinical Centre "Kragujevac", Svetozara Markovica 69, Kragujevac 34000, Serbia

Tel: 38134335572, Fax: 38134306800, E-mail: piki@medf.kg.ac.rs

(a) This is an Open Access article distributed under the terms of the Creative Commons Attribution Non-Commercial License (http://creativecommons.org/licenses/bync/3.0) which permits unrestricted non-commercial use, distribution, and reproduction in any medium, provided the original work is properly cited. cia, a syndrome of bone mineral depletions, surely represent important medical problems all over the world today. ${ }^{1,2}$ This constitutes one of the reasons why there is growing interest in the medical community for various aspects of long-lasting and insidious bone mineral disturbances, including chronic hypocalcemia. ${ }^{3}$ Several previous studies have described the epidemiological evidence connected osteoporotic fractures, low bone mineral density and antipsychotic medications, from adolescent to elderly populations, usually, but not obligatory, with multiple predisposing risks. ${ }^{4-8}$ Hyperprolactinemia, well-known adverse effect of some neuroleptic agents, was has been blamed to be the main affecter of bone homeostasis, 
probably by inducing hypogonadism and disturbing bone remodeling. ${ }^{9,10}$ However, in some patients with chronic schizophrenia other pathways could be more important because recent experimental evidence linked antipsychotic drugs and stimulation of osteoclast activity. ${ }^{11,12}$ Therefore, the mechanism of antipsychotic-induced bone and/or mineral loss has not been completely understood yet.

Surprisingly, researchers paid little attention to closer relationships between calcium homeostatic pathways and antipsychotic drugs. Two studies examined this issue, but did not report disturbances of serum calcium concentrations in patients treated with antipsychotics. ${ }^{13,14}$ On the other hand, antipsychotic drugs affecting urine calcium and phosphate concentrations left open the possibility for involvement of renal exchangers in drug action. ${ }^{15}$ The recent studies found significant association between the use of risperidone and hypocalcemia, based on the evidence coming from investigations of different designs. ${ }^{16,17}$ The latest review compiled sixteen studies investigating the link between schizophrenia, antipsychotic use and osteoporotic fractures. Important uncertainties still exists indicating the need for larger, prospective and more detailed research. ${ }^{18}$

In this paper, we hypothesized that patients taking antipsychotic drugs were prone to calcium depletion state which was also associated with other bone minerals and hormones. Due to very strict regulation of calcium metabolism we expected major oscillations of calcemia to occur only during the initial treatment changes, with consequent compensatory response, leaving either normal or slightly disturbed serum concentrations of parameters of bone homeostasis. In order to catch the early mechanisms, we focused prospectively on cases with newly introduced antipsychotic drug or dosing regimen and measured the parameters weekly, during the acute phase of the chronic mental disorders.

\section{METHODS}

We designed the clinical research as an interventional, nontherapeutic, prospective, time-series trial. The approach of serial measurements of parameters of physical health in the same subject with a mental disorder was used in both the research trials and the routine psychiatric practice. ${ }^{19,20}$ Study time-frame and visit arrangements were adjusted for expectations of more rapid, fluctuating changes in bone homeostasis after the introduction of an external trigger. ${ }^{21}$ In general, the study design was based on the experiences from numerous similar published research articles dealing with the topic, which have been referenced in the introduction and discussion sections.

Clinical Centre "Kragujevac", Kragujevac, Serbia, with its departments (psychiatry, clinical pharmacology, clinical biochemistry, endocrinology and nuclear medicine) was the study site. We included hospitalized subjects and outpatients in the screening, recruitment, study conduction and follow-up at the setting of everyday psychiatric practice. The study lasted from June 1st, 2011 (the first patient included) to October 3rd, 2011 (the last patient's follow-up). In general, the weekly assessments represented the study visit (baseline, 1st to 4th follow up) at which the total of five blood samples for each participant were scheduled. An independent, institutional Ethics Committee approved the study. Furthermore, after the subjects had been presented with the complete description of the study their written informed consent was obtained.

The subjects were enrolled if they satisfied the following inclusion criteria: adult male or female, 35-85 years old, suffering from schizophrenia, bipolar disorder or other neuropsychiatric disease with an acute phase of prominent psychotic symptoms (the first one or a new relapse episode), antipsychotic drug naïve or requiring a switching of the existing treatment to antipsychotic drug that they had not been taking in the previous month (including patients with the treatment noncompliance) or when the dosage was rapidly increased (according to the clinical judgment of the psychiatrist) and who voluntary gave their written informed consent. The exclusion criteria were: age younger than 35 and older than 85 years, pregnant and lactating women, subjects with any documented or clinically obvious condition or disease at baseline visit indicating the presence of pre-existing disorder of bone and mineral homeostasis within the period of an acute or a convalescing phase (e.g., fracture, infection, pancreatitis, rhabdomyolysis, acid-base or electrolyte disorder), subjects participating in another research study or patients refusing to give their informed consent in writing.

Total serum calcium concentration represented the primary outcome. The serum concentrations of magnesium, phosphorous, parathyroid hormone, vitamin $\mathrm{D}$, calcitonin, osteocalcin and C-telopeptide (collagen type 1 cross-links) constituted secondary outcomes. Albumin, creatinine, thyroid-stimulating hormone and free-levothyroxine indicated the control variables. A widely used formula, adjusted $[\mathrm{Ca}](\mathrm{mmol} / \mathrm{L})=$ total $[\mathrm{Ca}](\mathrm{mmol} / \mathrm{L})+0.02 \times[40$-[albumin $](\mathrm{g} / \mathrm{L})]$, served to adjust calcium levels for a given albumin concentrations, but only in one control data set, due to uncertainties regarding the most appropriate calculation method. ${ }^{22}$ Some variables were excluded (e.g., prolactin, 24-h urinary calcium excretion, cortisol, gonadal hormones) taking into account the properties of the study population, the main study objectives and the technical limitations of real-life care settings.

The patients were carefully examined and their medical records were retrieved for identification of the array of basal 
risk factors for osteoporosis, osteomalacia and calcium disturbance and other key parameters. ${ }^{23}$ Calcium, parathyroid hormone, thyroid-stimulating hormone and free-levothyroxine in baseline samples outside their respective reference ranges as well as baseline hypomagnesemia (if found) were also considered medically important as risk variables.

During the study, a research-trained nurse took a whole blood sample of sufficient volume (about $20 \mathrm{~mL}$ ) from the patient's cubital vein and quickly processed it to the clinical biochemistry facility, at ambient temperature. The sample underwent centrifugation and serum separation with final storage at $-25^{\circ} \mathrm{C}$. Shortly after completion of the active study phase, a clinical biochemist performed serum sample analysis using Beckman Coulter UniCel DxC 800 Synchron Clinical System (Beckman Coulter Inc., Brea, USA) for calcium (total calcium), magnesium, phosphorous (inorganic phosphorous), albumin and creatinine. Cobas e411 chemical analyzer (Roche Diagnostics GmbH, Mannheim, Germany) served as the platform for total 25-hydroxyvitamin D [25(OH) $\mathrm{D}$ : 25-hydroxyvitamin $\mathrm{D}_{3}$ and 25-hydroxyvitamin $\mathrm{D}_{2}$ ], osteocalcin (N-MID osteocalcin) and C-telopeptide ( $\beta$-isomerized C-terminal telopeptides, $\beta$-CTx) measurements. In Nuclear Medicine Department research staff measured serum concentration of parathyroid hormone (PTH), calcitonin (CT), thyroid-stimulating hormone (TSH) and free-thyroxine $\left(\mathrm{FT}_{4}\right)$ using Wallac Wizard 1470 Gamma counter (PerkinElmer Life Sciences, Wallac Oy, Turku, Finland). An endocrinologist explored bone mineral density (BMD) of the hip and lumbar spine (L1-4) using dual-energy X-ray absorptiometry (DXA) equipment (Hologic Discovery W, Hologic Inc., Bedford, USA). The details about the exact chemical reactions and methods of measurements are described in the manufacturers' product manuals.

Sample size calculation aimed at detection of the decrease of serum calcemia (primary variable) in the final blood sample from the baseline of $\geq 5 \%$ (primary outcome) as statistically significant, for paired, one-sample analysis. The basic parameters came from our previous experience about serum calcemia fluctuation and its variability under the antipsychotic therapy. The sample size calculator was imputed with a difference of $0.15 \mathrm{mmol} / \mathrm{L}$, standard deviation of 0.20 $\mathrm{mmol} / \mathrm{L}, \alpha=0.05$ and study power of 0.8 and then, corrected (increase) the output for assumption of nonparametric test and expected level of missing values. Therefore, the final results of at least 30 study subjects appeared.

The study database included data of all the patients for whom at least two blood samples were collected and successfully analyzed (baseline value and a subsequent change from it). The missing values, as a rule, remained as such (empty) except for only one patient where the extreme outliers for the five analytes were found (despite repeated measurements) and such five inputs were replaced according to "carried backward" approach. Statistical methods incorporated descriptions, correlation, regression, repeated-measures and pairedsample analysis, chi-square test and binary logistic regression with the test type chosen according to the distribution pattern of the source data for the tested variable (normal or skewed distribution). The Anatomical Therapeutic Chemical (ATC) classification system and the Defined Daily Dose (DDD) of World Health Organization drug statistics methodology, as well as chlorpromazine-equivalent doses, were used as tools for determining the utilization level of antipsychotic drugs (http://www.whocc.no). ${ }^{24}$ The sum of changes from the baseline served as a useful variable to aggregate small fluctuations of calcemia, based on the previous report from another interventional research. ${ }^{25} \mathrm{~A}$ significance threshold was determined at probability of null hypothesis of 5\% or less for all statistical calculations with two-tailed approach.

\section{RESULTS}

\section{Study population consisted of mature adults with a chronic mental illness}

The main characteristics of the study patients are presented in the Table 1 . The majority of patients had one neuropsychiatric diagnosis $(28,73.7 \%)$, eight subjects had two diagnoses (21.1\%) and two participants had three neuropsychiatric diseases, of the total of 50 entities, with schizophrenia being the most frequent disorder (in 11 patients). The total of 26 somatic diseases were recorded in 25 patients (65.8\%), 51 times (median 2, range 1-5) and the most common were the cardiovascular ones (recorded 21 times).

Study patients took 48 different drugs, in total of 194 patients' prescriptions. Top five prescribed drugs were: diazepam (prescribed for 21 patients), haloperidol (18), lorazepam (18), risperidone (13) and glucose isotonic infusion solution (8). The mean defined daily doses (standard deviation) of antipsychotics per 100 patient-days was $77.6 \pm 53.6(n=38$, range 12.5-237.5). The mean of chlorpromazine-equivalent dose per day, per patient, within the study period was 203.4 $144.3 \mathrm{mg}$ ( $\mathrm{n}=38$, range $30-690 \mathrm{mg}$ ). Previous chlorpromazine-equivalent dose for subjects in whom we identified full compliance to dosing regimen of another (or the same) antipsychotic(s) prescribed just before entering the study was $109.0 \pm 70.9 \mathrm{mg}(\mathrm{n}=10$, range $30-280 \mathrm{mg})$.

Other details about patients' characteristics are presented in Supplementary Results R1 (in the online-only Data Supplement). 


\section{Calcemia predominantly decreased}

The serum calcium values, with changes from the baseline, together with other measured parameters of calcium homeostasis are presented in the Table 2. In general, calcemia decreased in fluctuating pattern, independently of the presence

Table 1. The characteristics of study subjects

\begin{tabular}{ll}
\hline \multicolumn{1}{c}{ Variable } & \multicolumn{1}{c}{ Value } \\
\hline Gender (male/female) & $19(50.0) / 19(50.0)$ \\
Age (years) & $52.2 \pm 11.1(38,36-77)$ \\
High $(\mathrm{cm})$ & $171.2 \pm 10.5(38,147-195)$ \\
Weight $(\mathrm{kg})$ & $82.0 \pm 15.6(38,53-115)$ \\
Body mass index $\left(\mathrm{kg} / \mathrm{m}^{2}\right)$ & $28.0 \pm 4.9(38,20.7-39.9)$ \\
Inhabitance (urban/rural) & $28(73.7) / 10(26.3)$ \\
Home comfort & $21(55.3) / 17(44.7)$ \\
(good/substandard) & \\
Education level ${ }^{*}$ & $2(5.3) / 9(23.7) / 5(13.2) /$ \\
& $21(55.3) / 0(0) / 1(2.6)$ \\
Employment $^{\dagger}$ & $14(36.8) / 11(28.9) / 5(13.2) /$ \\
& $8(21.1)$
\end{tabular}

Diet \& habits

\begin{tabular}{ll} 
Appetite (well/bad) & $28(73.7) / 10(26.3)$ \\
Proteins (normal/little) & $29(76.3) / 9(23.7)$ \\
Milk diaries (normal/little) & $34(89.5) / 4(10.5)$ \\
Salt (little/normal/high) & $2(5.3) / 35(92.1) / 1(2.6)$ \\
Fish (normal/little) & $20(52.6) / 18(47.4)$ \\
Coffee (cups) & $2.9 \pm 1.2(33,1-6)^{\|}$ \\
Smoking (years) & $22.4 \pm 8.8(19,6-35)^{\|}$ \\
Physical activity (hours) & $5.3 \pm 3.9(23,1-12)^{\pi}$ \\
Somatic diseases & $2.0 \pm 1.2(25,1-5)^{\Uparrow}$ \\
Drugs & $5.1 \pm 2.0(38,2-10)$ \\
DXA (normal/abnormal) & $22(57.9) / 16(42.1)$ \\
T-score & $-1.12 \pm 0.66(24,0.4 \text { to }-2.6)^{\top}$ \\
Z-score & $-0.16 \pm 1.07(38,2.90$ to -3.00$)$ \\
Serum albumin (g/L) & $47.0 \pm 7.0(38,26-70)$ \\
Risks ${ }^{\ddagger}$ & $3.6 \pm 1.6(38,1-7)$ \\
Previous hospitalizations & $3.0 \pm 1.6(35,1-5)^{\pi}$ \\
Duration of psychotic illness & $14.4 \pm 10.3(1-45)$ \\
(years) & \\
Treatment settings & $17(44.7) / 21(55.3)$ \\
Days (in the study) & $25.4 \pm 8.1(38,4-38)$ \\
\hline
\end{tabular}

Numbers represent absolute values (percentages), the means \pm standard deviations, number of patients and ranges, as appropriate. *uneducated/elementary/high school (first degree)/high school (final degree)/college/university, ${ }^{\dagger}$ retired/jobless/employed/physi-

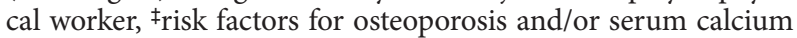
disturbances, §outpatient/inpatient (during the study), "only for drinkers/smokers, "Tzero/missing inputs are excluded. DXA: dualenergy X-ray absorptiometry of risk factors and other confounders and with some difference between antipsychotic drugs.

During the antipsychotic treatment, calcemia significantly and negatively correlated with study days (Pearson $\mathrm{r}=-0.216$, $\mathrm{p}=0.005, \mathrm{n}=165)$ in a pattern of linear regression $(\mathrm{y}=-0.003 \times$ $+2.439, \mathrm{p}=0.005$ ) (Figure 1). Paired sample analysis showed a significant difference (decrease) of calcium concentration between 1st (baseline) and 5th (week 4) serum sample ( $t$ test, $\mathrm{df}=24, \mathrm{p}=0.022$ ) (Figure 1). However, the fluctuations of both the absolute calcemia and the changes from baseline across the study (repeated measure analysis for five visits) did not reach the level of statistical significance. In addition, the changes in serum calcemia were, to a great extent, within the reference range. The mean of all calcium concentrations was $2.40 \mathrm{mmol} / \mathrm{L}$ with the standard deviation of $\pm 0.15, \mathrm{n}=165$ ). In only 5 blood samples (from five patients) it dropped to the hypocalcemic range $(<2.1 \mathrm{mmol} / \mathrm{L}$ ) and in 8 samples (from seven subjects) it rose above the upper normal limit $(>2.6$ $\mathrm{mmol} / \mathrm{L}$ ).

On the other side, the mean of all changes of calcemia from the baseline was negative $(-2.6 \pm 5.7 \%, \mathrm{n}=127)$ with significantly more instances of decreases than increases among all serum samples ( 78 vs. 49 , chi-square, $\mathrm{df}=1, \mathrm{p}=0.010$ ). Moreover, significantly more patents had a negative sum of changes from the baseline calcemia $(n=28)$ than positive ones $(\mathrm{n}=10)$ (chi-square, $\mathrm{df}=1, \mathrm{p}=0.004)$ dividing the cohort into two subgroups: those susceptible to depletion and those prone to accumulation of serum calcium.

\section{Bone mineral ions correlated with calcium}

\section{Magnesium}

The analysis of repeated measures showed a statistically significant difference within 4-week magnesemia for both the absolute values (Friedman test, $\mathrm{df}=4, \mathrm{p}=0.014, \mathrm{n}=24$ ) and the changes from the baseline (Friedman test, $\mathrm{df}=3, \mathrm{p}=0.042$, $\mathrm{n}=24$ ), respectively. There were much more negative than positive changes of serum magnesium levels from the baseline in all serum samples (negative changes in 86 and positive ones in 41 ; $\mathrm{df}=1, \mathrm{p}=0.001$ ). There was a significant positive correlation between both magnesium and calcium serum concentrations $(\mathrm{r}=0.486, \mathrm{p}<0.001, \mathrm{n}=165)$ and their respective changes from the baseline $(\mathrm{r}=0.685, \mathrm{p}<0.001, \mathrm{n}=127)$ (Figure 2). Concerning all collected blood samples, there were significantly greater odds to find simultaneous fall from the baseline of both calcium and magnesium concentrations than their respective discrepancies [ $\mathrm{n}=127,63 / 15$ vs. $23 / 26$, chi-square, $\mathrm{p}<0.001$; odds ratio $(\mathrm{OR})=4.75,95 \%$ confidence intervals (CI) 2.14-10.51]. 


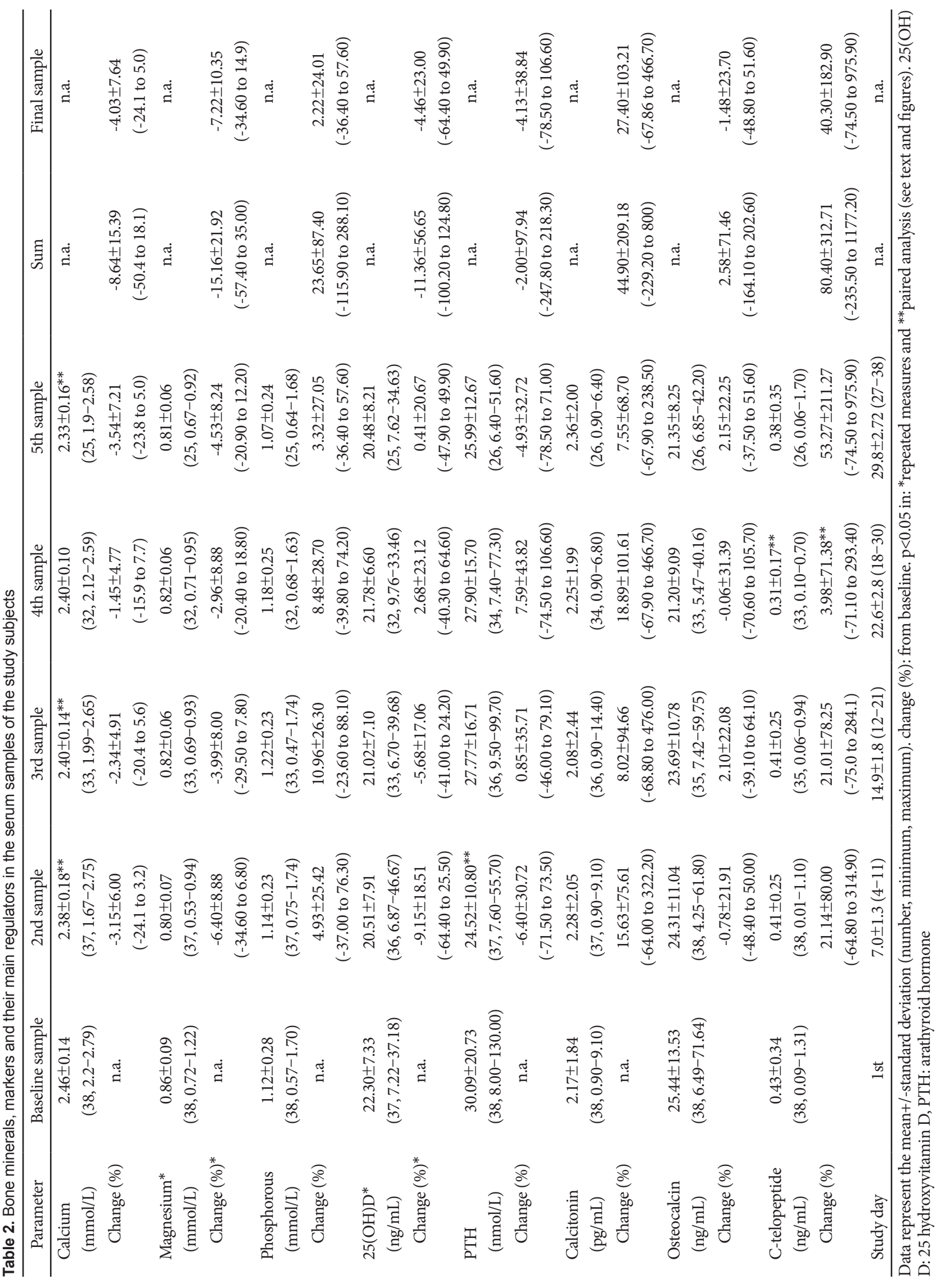




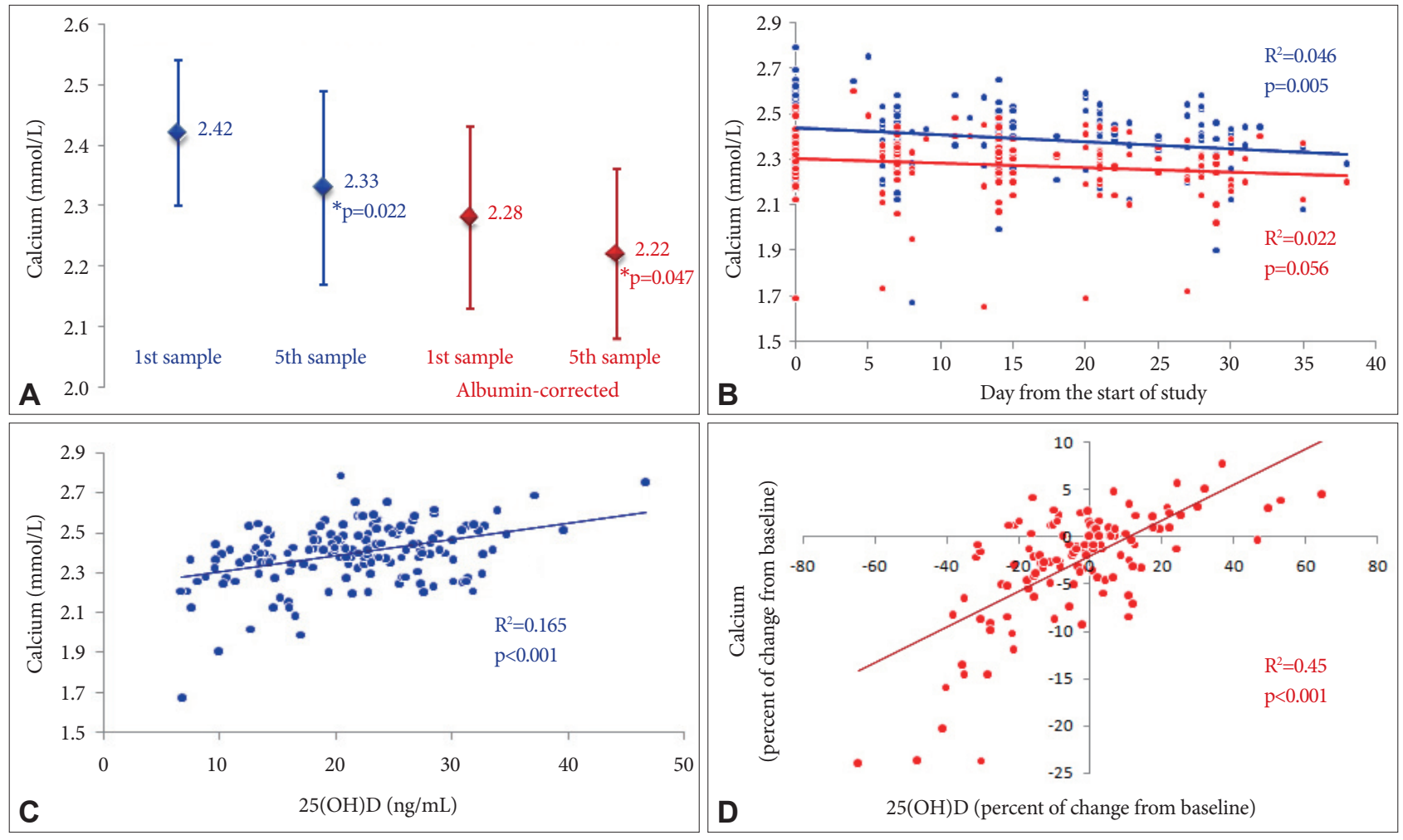

Figure 1. Changes of total measured and albumin-corrected serum calcium concentrations ( $A$ and $B$ ) and correlation with 25-hydoxivitamin $D$ values $(C$ and D). A: Paired sample t-test analysis ( $n=25$, for each of the blood sample sets), values represent the mean and the (one) standard deviation.
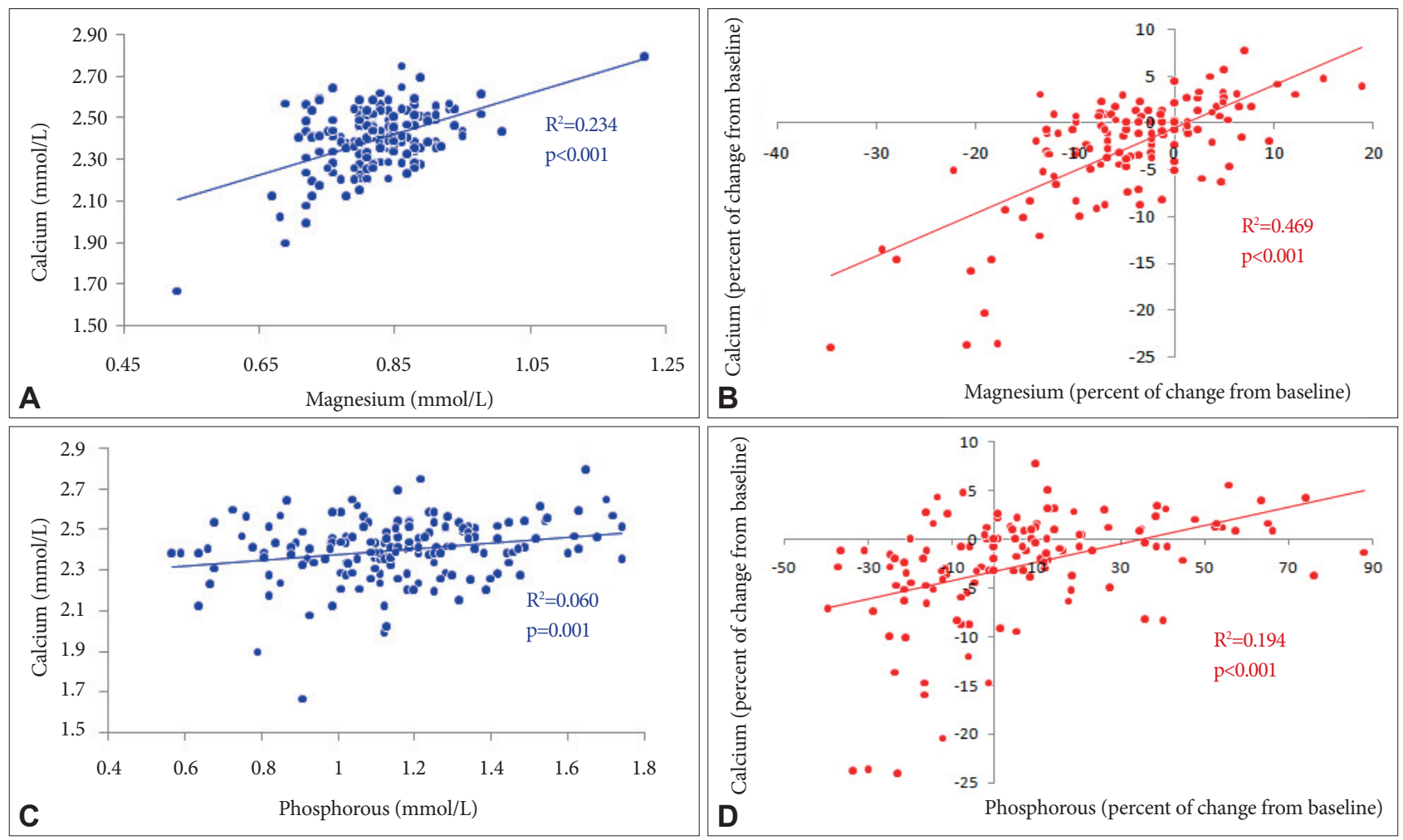

Figure 2. Correlation of serum calcium concentrations $(A$ and $C)$ and their changes $(B$ and $D)$ from the baseline with serum magnesium $(A$ and $B)$ and phosphorous $(C$ and $D)$ respective values. 


\section{Phosphorous}

Phosphorous serum concentrations and changes from the baseline during the study, in statistical terms, neither differ significantly from each other nor showed a particular, significant pattern. However, they did correlate with calcium parameters in the same direction. There was a significant positive correlation between phosphorous and calcium serum concentrations $(\mathrm{r}=0.246, \mathrm{p}=0.001, \mathrm{n}=165)$ and their changes from the baseline $(\mathrm{r}=0.441, \mathrm{p}<0.001, \mathrm{n}=127)$ (Figure 2$)$. In addition, concerning all collected blood samples, there were significantly greater odds to find simultaneous fall from the baseline of both calcium and phosphorous concentrations than their respective discrepancies ( $n=127,45 / 33$ vs. 9/40, $\mathrm{df}=1, \mathrm{p}<0.001 ; \mathrm{OR}=6.06,2.59-14.20)$.

On the other hand, calcium-phosphorous ion (CaxP) product did not change significantly during the study (ANOVA, $\mathrm{df}=4, \mathrm{p}=0.224, \mathrm{n}=24)$. The mean values and standard deviations $\left(\mathrm{mmol}^{2} / \mathrm{L}^{2}\right)$ of the product at visits are: $2.77 \pm 0.78(\mathrm{n}=38)$, $2.72 \pm 0.61$ (37), $2.97 \pm 0.62$ (33), $2.84 \pm 0.64$ (32) and $2.51 \pm 0.62$ (25). Only 9 values fall below the product of lower reference ranges of calcium $(2.1 \mathrm{mmol} / \mathrm{L})$ and phosphorus $(0.8 \mathrm{mmol} /$ L) (3 at baseline and 1, 1, 1, 3 at subsequent visits) which was sometimes considered to be associated with impaired bone mineralization.

\section{A calcium regulator fluctuated}

\section{Parathyroid hormone}

In general, fluctuations of PTH serum values did not reach statistical significance. Only borderline significance in the difference (decrease) of PTH concentration between 1st (baseline) and 2nd (week 1) serum samples was detected (Wilcoxon signed-rank test, $\mathrm{p}=0.044, \mathrm{n}=37$ ). We were unable to demonstrate any other statistically significant relationships between PTH and calcium parameters, too (Figure 3).

\section{Vitamin D}

Slight but statistically significant difference was found within the subjects' weekly serum of vitamin D [25(OH)D] concentrations (ANOVA, $\mathrm{df}=4, \mathrm{p}=0.044, \mathrm{n}=24$ ), but fluctuations were more for the changes from the baseline (ANOVA, $\mathrm{df}=3, \mathrm{p}=0.005, \mathrm{n}=24$ ). A significant difference (decrease) was detected between 1st (baseline) and 2nd (week 1) samples ( $\mathrm{t}$ test, $\mathrm{df}=35, \mathrm{p}=0.004, \mathrm{n}=36$ ). Vitamin $\mathrm{D}$ values positively correlated with the calcium ones both in the absolute serum concentrations $(\mathrm{r}=0.407, \mathrm{p}<0.001, \mathrm{n}=163)$ and in the changes from the baseline $(\mathrm{r}=0.671, \mathrm{p}<0.001, \mathrm{n}=126)$ (Figure 1). Moreover, the patients who had a negative sum of calcemia changes from the baseline were also in about nine times greater odds to have the negative sum of vitamin $D$ changes $(O R=8.75$,
$1.49-51.50 ; n=37,20 / 8$ vs. $2 / 7$, chi-square, $p=0.026$ ). Finally, concerning all collected blood samples, there were significantly greater odds to find simultaneous fall from the baseline of both calcium and vitamin $\mathrm{D}$ concentrations than their respective discrepancies $(\mathrm{n}=126,57 / 21$ vs. $13 / 35, \mathrm{df}=1, \mathrm{p}<$ 0.001; OR=7.31, 3.25-16.42).

\section{Calcitonin}

Near a half of the calcitonin concentrations in the collected serum samples were bellow the detection limit of the used analytical method ( $<1 \mathrm{pg} / \mathrm{mL} ; 76$ of 171). Across the study visits, frequencies of such values did not significantly change and, consequently, we decided not to perform hypothesis testing. For the purpose of data description only, all calcitonin concentration being less than cut off level were counted as $0.9 \mathrm{pg} / \mathrm{mL}$ (Table 2) and the relationships with calcium parameters is presented in the Figure 3.

\section{Bone markers oscillated thinly}

\section{Osteocalcin}

Absolute serum values of osteocalcin (a marker of bone synthesis/osteoblastic activity) as well as its changes from the baseline concentrations did not fluctuate significantly during the study. On the other side, osteocalcin showed low positive correlation with calcemia for all changes from baselines ( $\mathrm{r}=$ $0.192, \mathrm{p}=0.030, \mathrm{n}=127$ ) (Figure 4). Other associations remained below the significance threshold.

\section{C-telopeptide}

C-telopeptide, a marker of bone resorption/osteoclastic activity, as a whole, did not change during the study for neither absolute serum concentration nor changes from the baseline. However, in week three (4th sample) there was a notable decrease of absolute and relative values (Wilcoxon signed-rank test, $\mathrm{p}=0.035$ and $\mathrm{p}=0.017$, respectively). In addition, the concentrations of $\mathrm{C}$-telopeptide negatively correlated with the calcium ones $(\mathrm{r}=-0.178, \mathrm{p}=0.022, \mathrm{n}=165)$ (Figure 4).

\section{Adjusting for known confounders confirmed the trend}

In general, adjusting calcium concentration for albumin levels shifted the results to lower points. Although fluctuations of albumin-corrected calcemia did not fit significantly with the study days (Pearson $\mathrm{r}=-0.149, \mathrm{p}=0.056$ ), some other variables confirmed the trend of total (unadjusted) calcium (Figure 1). The significant difference (decrease) of albumincorrected calcemia between 1st (baseline) and 5th (week 4) samples (Wilcoxon signed ranks test, $\mathrm{p}=0.047, \mathrm{n}=25$ ) was noted (Figure 1). Fluctuations of the changes from the baseline across the study (repeated measure analysis for five visits) 


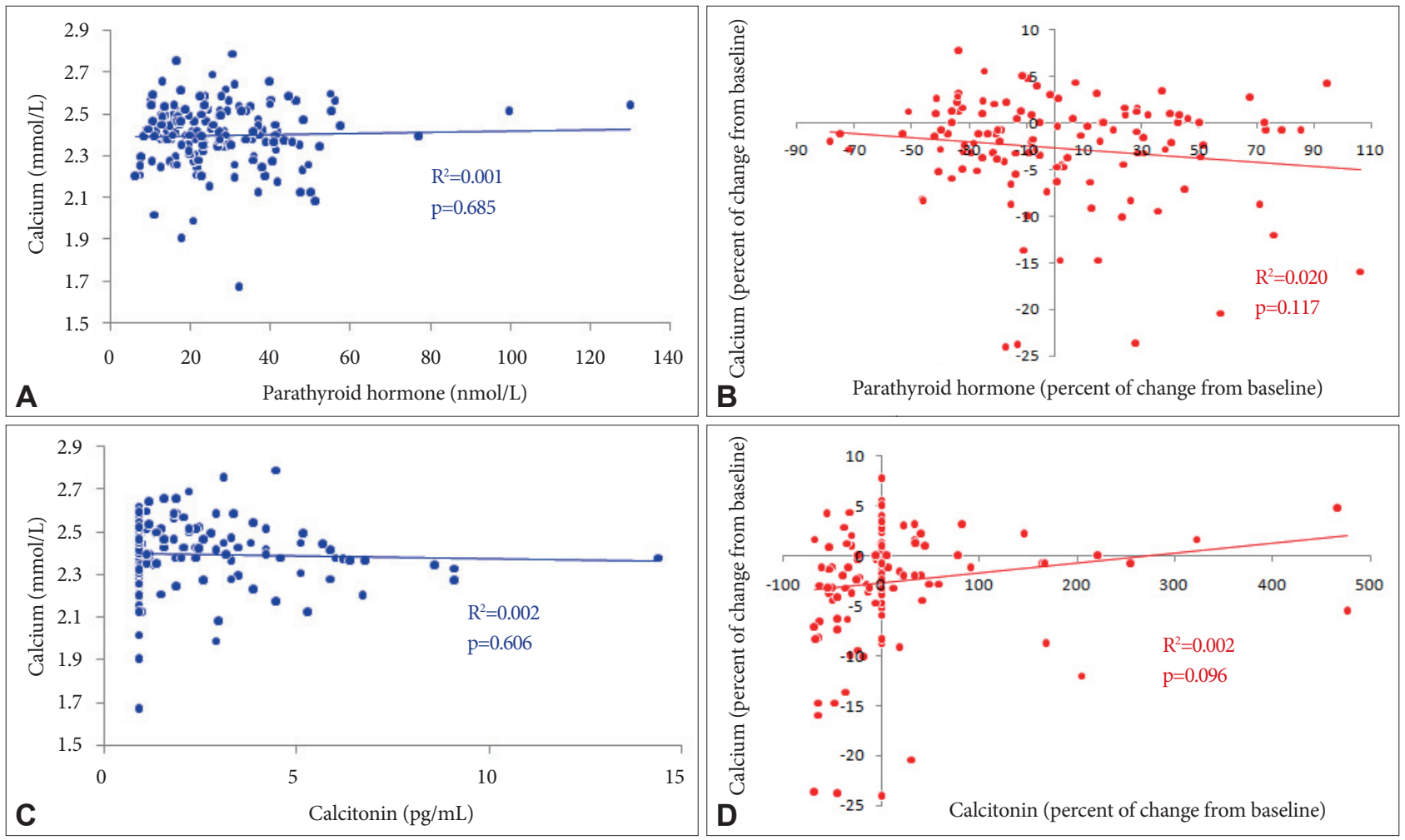

Figure 3. Correlation of serum calcium concentrations ( $A$ and $C$ ) and their changes from the baseline (B and $D)$ with serum parathyroid hormone $(A$ and $B)$ and calcitonin $(C$ and $D)$ respective values.

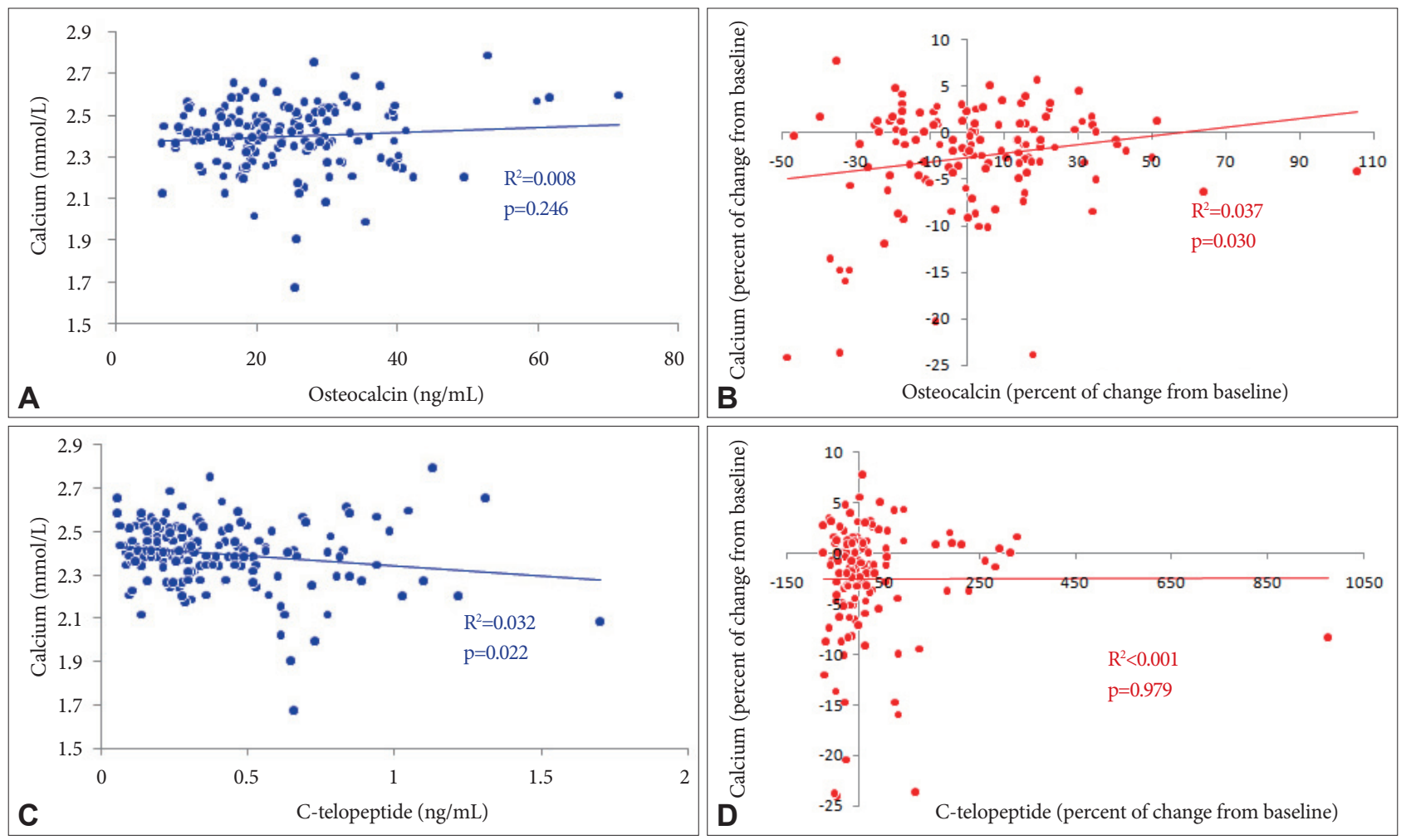

Figure 4. Correlation of serum calcium concentrations ( $A$ and $C$ ) and their changes from the baseline (B and $D)$ with serum osteocalcin (A and $B$ ) and $C$-telopeptide $(C$ and $D)$ respective values. 


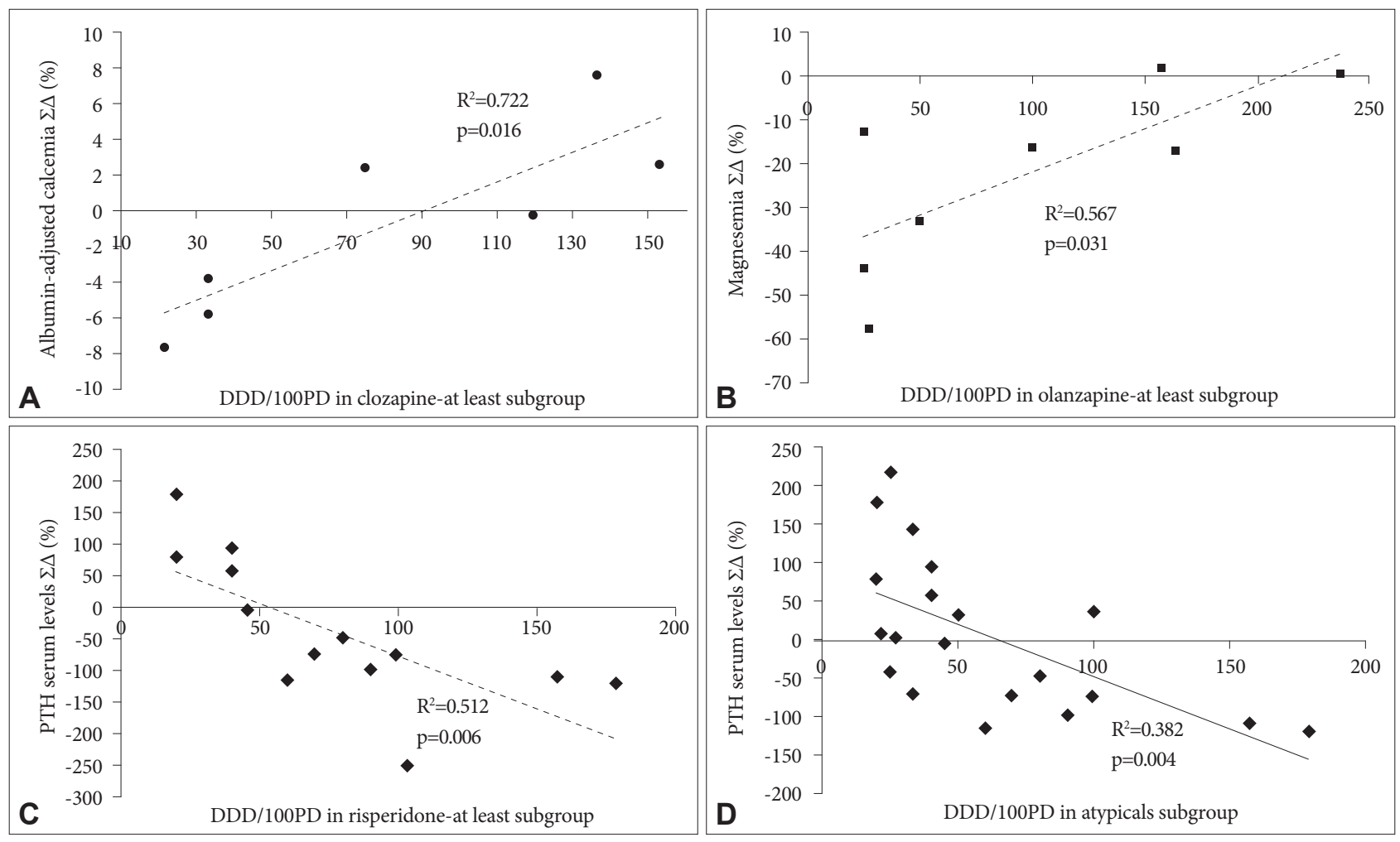

Figure 5. Dose-effect relationships of selected parameters [expressed as a sum $(\Sigma)$ of changes $(\Delta)$ from the baseline-SD] within of subgroups of subjects taking clozapine (A), olanzapine (B), risperidone (C) or atypical antipsychotic(s) (D).

reached statistical significance (Friedman test, $\mathrm{df}=3, \mathrm{p}=0.048$, $\mathrm{n}=24$ ) including a difference between 2 nd (week 1$)$ and final (5th) samples (Wilcoxon signed ranks test, $\mathrm{p}=0.005, \mathrm{n}=24$ ).

There were 9 blood samples (from five patients) in which albumin-adjusted calcium dropped to the hypocalcemic range $(<2.1 \mathrm{mmol} / \mathrm{L})$ and there was no sample in which it rose above the upper normal limit $(>2.6 \mathrm{mmol} / \mathrm{L})$. The findings of the decreased value of calcemia in a blood sample from the baseline increased the odds to find simultaneously the decreased value of albumin-adjusted calcemia, too, by a factor $\sim 4$ (49/29 vs. $14 / 35$; OR=4.22, 1.95-9.14, $\mathrm{p}<0.001)$. Taking into account all blood samples, the mean albuminadjusted calcemia was $2.28 \pm 0.14 \mathrm{mmol} / \mathrm{L}(\mathrm{n}=165,1.65$ to 2.60) and the mean change from the baseline was $-0.92 \pm 3.8 \%$ $(\mathrm{n}=127,-17.0$ to 7.7$)$.

Using binary logistic regression approach we explored the influence of plenty of other relevant risk factors which were found in the study subjects: inherited demographics (female gender, age $>60$ years, family history of osteoporosis, menopause $<47$ years), poor habits and nutrition (smoking, sedentary lifestyle or inadequate physical activity, low calcium intake, high caffeine daily intake with 4 cups, $\sim 600 \mathrm{~mL}$, of coffee or more, high salt intake, baseline vitamin $\mathrm{D}$ deficiency defined as 25-hydroxyvitamin D serum level of less than $20 \mathrm{ng}$ per milliliter) and somatic diseases (diabetes mellitus, prior fracture on minor trauma in adulthood, hyperthyroidism, epilepsy). The five cases of basal hypercalcemia and a basal hyperparathyroidism value as well as the DXA-confirmed low bone density (T-score $<-1.0$ or Z-score $\leq-2$ ) were also included in the risk variables. The list of analyzed risk factors also included drugs of interests: antipsychotics (haloperidol, risperidone, olanzapine, clozapine) together with their cumulative dose (DDD per 100 patient days), other psychotropic and neurological drugs used by five or more study subjects (diazepam, lorazepam, zolpidem, sertraline, trazodone) and drugs known to induce osteoporosis (valproate, aluminum-containing antacids). In order to overcome the low prevalence of some of the abovementioned risks in our study sample, we used an additional, summary variable the number of risk factors, for each patient.

No one of those confounders (their frequencies or their values) did differ significantly between the two subgroups of patients, the ones with total decrease (negative sum of changes) and the others with total increase of serum calcemia (positive sum of changes). On the other side, we noted moderate correlations of baseline calcemia with: baseline magnesemia $(\mathrm{r}=0.470, \mathrm{p}=0.003, \mathrm{n}=38)$, baseline phosphorous $(\mathrm{r}=0.416, \mathrm{p}=0.009, \mathrm{n}=38)$, and baseline $25(\mathrm{OH}) \mathrm{D}$ concentrations $(\mathrm{r}=0.394, \mathrm{p}=0.016, \mathrm{n}=37)$. 


\section{Antipsychotic subgroup analysis}

Our study was underpowered (and not primarily aimed) to confirm the differences between the prescribing of individual antipsychotic drugs at primary study outcome. However, there were subtle significant associations of some study variables and separate study subgroups, which are, in detail, presented within Supplementary Results R2 (in the onlineonly Data Supplement). Taking into account the possible dose-response relationships in the whole study population we were unable to demonstrate the statistical significance of calcemia changes (or changes in other calcium regulators) and antipsychotic DDD per 100 subject days. On the other hand, in the patients taking clozapine a significant positive correlation with the sum of changes for albumin-adjusted calcemia appeared ( $\mathrm{r}=0.849, \mathrm{p}=0.016, \mathrm{n}=7)$, in those who took olanzapine a significant positive correlation with magnesemia sum of changes occurred $(r=0.753, p=0.31, n=8)$ and in the subjects with risperidone prescription a significant negative correlation with the sum of changes for parathyroid hormone serum concentrations emerged $(\mathrm{r}=-0.716, \mathrm{p}=0.006$, $\mathrm{n}=13$ ). If typical antipsychotics were excluded and the dopamine/serotonin drugs remained (clozapine in 3 patient, olanzapine in 6 subjects, risperidone in 12 ones) only a significant negative correlation with parathyroid hormone concentration still remained $(\mathrm{r}=-0.618, \mathrm{p}=0.004, \mathrm{n}=20)$ (Figure 5).

\section{Gender subgroup analysis}

Taking into the account the well-known importance of gender differences for bone homeostasis, we investigated its influence on other minerals and hormones. There was no statistically significant association of gender and changes of phosphorous, magnesium, parathyroid hormone, vitamin D, calcitonin, osteocalcin and C-telopeptide. In addition, we performed a series of separate statistical tests independently for male and female subgroups. We looked for a significant association of identified risks and study analytes using Pearson's correlation (for two continuous variables), t-test or Wilcoxon signed-rank test (for a continuous outcome and a categorical risk) and logistic regression (for binary outcomes). There were no significant links with the outcome variables related to calcium, but two other associations emerged consistently, physical activity and osteocalcin for males and body mass index and C-telopeptide for females. In males, but not in female study subjects, adequate physical activity was protective factor for the appearance of the negative sum of changes of the baseline of osteocalcin (OR=0.08, 95\% CI 0.01-0.99, $\mathrm{p}=0.045$ ). On the other side, in females, but not in male study patients, higher body mass index was a risk factor for appearance of the positive sum of changes from the baseline of serum Ctelopeptide ( $\mathrm{OR}=1.26,95 \%$ CI 1.01-1.57, $\mathrm{p}=0.041$ ).

\section{DISCUSSION}

Our study presents the evidence that the treatment with antipsychotics during routine psychiatric care was associated with the decrease of serum calcium concentration of small, but detectable magnitude, which, in the long run, could have clinical consequences. In serum samples of study subjects' the calcium concentration trends which were, in general, directed to lower values/decreasing, positively correlated with the trends of magnesium, phosphorous, 25-hydroxyvitamin $\mathrm{D}$ and osteocalcin. Therefore, the results support our hypothesis that antipsychotic treatment predisposes to significant oscillation of homeostasis of calcium and other bone minerals and hormones, with more frequent inclination to the state of their depletion. Beside osteoporotic process, the well-documented increased fracture risk in patients treated from severe mental disorders could involve other, overlapping and/ or, more or less, independent mechanisms.

It seems that the important event for lowering calcemia in our patients included the inhibition of vitamin D activity at the level of either intestinal absorption or renal reabsorption. ${ }^{26}$ Both processes are highly dependent on vitamin $\mathrm{D}$ which, by means of its final active metabolite $1,25(\mathrm{OH})_{2} \mathrm{D}_{3}$, induced synthesis of calcium selective channels within enterocytes and renal distal tubular cells (TRPV5-6). ${ }^{27}$ Other researchers also reported that in patient populations of variable demographic characteristics and environmental conditions many subjects suffering from schizophrenia had low vitamin D (25-hydroxyvitamin D) serum concentration including those taking different antipsychotic drug regimens. ${ }^{28-30}$ Major vitamin D metabolizing enzymes belong to cytochrome-type molecules ${ }^{31}$ and two studies have reported that antipsychotic drugs (in vivo and in vitro) could regulate activity of a couple of cytochromes from rat liver in both directions, up and down. ${ }^{32,33}$ The relative contribution of antipsychotics, disease and/or other baseline risks to the observed effect and their exact mechanism of action remained to be explored further.

Maintaining phosphate serum levels partially depends on vitamin $\mathrm{D}$ activity, too, due to its stimulation of active intestinal transport (primarily in low phosphate intake) and, therefore, this could contribute to low serum levels of phosphate detected in our study. ${ }^{34}$ On the other hand, vitamin $\mathrm{D}$ in humans probably does not significantly contribute to regulation of magnesium homeostasis. ${ }^{35}$ In addition, calcemia inversely links with renal magnesium and phosphate reabsorption which is the main arm of their regulatory pathways. ${ }^{26}$ Therefore, additional mechanism for lowering these ions probably existed in our patients.

It is well known that drugs could cause hypocalcemia, hy- 
pomagnesemia and hypophosphatemia by different mechanism (including those in the kidney), sometimes simultaneously and with associated vitamin D deficiency. ${ }^{35-37}$ Polydipsia, a state in which calcium and magnesium urinary excretion increase, appeared together with low bone density in the subset of patients with schizophrenia and it could not be excluded in our study population. ${ }^{38}$ Renal absorption of calcium in thick ascending limb of loop of Henle is paralleled with magnesium co-transport and hypomagnesemia often co-exists with hypocalcemia, further contributed to it, through inhibition of release of parathyroid hormone. ${ }^{39}$

In our study we have seen some kind of a blunted parathyroid hormone response on serum calcium oscillations, the notion further supported with dose-analysis of risperidone/ atypical subgroup. In another similar research parathyroid hormone also did not change in the majority of patients taking antipsychotics. ${ }^{40}$ The knowledge that the levels of parathyroid hormone within a reference range in the circumstances of present hypocalcemia indicates, in fact, its inappropriate response and that the hormone inhibits renal 24-hydroxylase (which convert 25-hydroxyvitamin D into inactive form) additionally support our findings. ${ }^{31,41}$ Finally, membrane bound calcium-sensing receptor (CaR), which is the main regulator of parathyroid hormone secretion, is also present in tubular cells of thick ascending loop of Henle and distal convoluted tubule where it affects cation transport. ${ }^{42}$ Researchers have just reported that cinacalcet, an allosteric modulator of $\mathrm{CaR}$, shared some its molecular targets with antipsychotic drugs. ${ }^{43}$

Based on the presented results, the dynamics between the main pathways might be linked with the hypothesis of our study. It could be hypothesized that the mechanisms which were involved in the decrease of serum calcium in our patients could, directly or indirectly, affect the following molecular targets: vitamin D metabolizing enzymes (25-hydroxylase inhibition, 24-hydroxylase induction), $\mathrm{Na} / \mathrm{K} / 2 \mathrm{Cl}$ transporter in tubular cells of thick ascending loop of Henle (inhibition) or calcium-sensing receptor of parathyroid cells (stimulation). The common results of all these changes was the redistribution of ions to the bone and other peripheral compartments as well as the increased tubular flow which constituted the next, possible non-receptor mediated mechanisms. Lowering of serum calcium activated regulatory systems, but their response was suboptimal and residual depletion of the cation remained. Magnesium and phosphate finally escape of such action of antipsychotic drugs because their ultimate regulation is rather influenced by dietary intake and passive membrane fluxes than calcium-specific homeostatic mechanism.

Limitations of our study force careful considerations before addressing the validity of the results and, particularly, possible causal relationships between antipsychotics and se- rum ionic change. The observed variation of ion blood concentrations might randomly appear due to regression to the mean which threatened the research without a control group. A type of selection bias which depends on admission-rate issues could not be excluded; this bias could reduce the representativeness of our study population and, therefore, the generalizability of results to other communities. One should always consider possibility for confounding because we did not tackle some important factors like prolactinemia (due to logistic constraints) or serum levels of gonadal/stress-response hormones (due to primary hypothesis restriction). ${ }^{44,45}$ Multiple statistical calculations could also increase the likelihood for the false-positive results (type I error) and, together with bias (if it really exists), this could result in high statistical significance.

We do believe that our study subjects represent a group which had some distinctive characteristics, but there are general determinants contributing more than the methodological bias, yet. Firstly, the radiation dose delivered during DXA examination precluded the inclusion of the patients younger than 35 years, due to formal ethical constraints. This greatly limited the available pool of eligible patients (particularly those being naïve to the treatment with major psychotropic drugs) and we decided to screen subjects from a wider group of mental diseases with psychotic features inevitably representing a rather heterogeneous group. Furthermore, we focused on those with a newly introduced antipsychotic drug or switching to a drug with generally much higher equivalent doses, assuming it to act as a novel trigger for the previously established calcium homeostatic equilibrium. Secondly, the population here is experiencing the long lasting socio-economic transition and the aging trends, and the prevalence of common risk factors (smoking, inappropriate dietary habits, alcohol abuse, physical inactivity, obesity, stress, hypertension, hypercholesterolemia) and socio-economic difficulties adversely affect community health status. ${ }^{46}$ Therefore, our results must not be directly extrapolated to general population of antipsychotic-taking subjects. Instead, the careful assessment of an adult in the mature age with several somatic diseases, risk factors for bone and mineral disturbances and multiple medications (whose importance was partially revealed in our subgroup analyses of gender and drug dose) is the first and the foremost advice for the practicing psychiatrists.

Other methodological limitations might play much less significant role, if any, in undermining the validity of our results. For example, two thirds of the women who participated in the study were postmenopausal, putting them in risk category without the necessity for gonadal hormones measurement. Despite the small size of the sample, our study was sufficiently powered to detect the difference in primary vari- 
able as no other analyte than calcium showed significant change in the primary outcome. In addition, for several important study outcomes we, together with probability of type I error ( 1 in 20 threshold), also presented the measures of association (OR) with their confidence intervals, in order to decrease influence of chance. The strength of such association, temporal sequence of exposure and outcome, and the abovediscussed existing knowledge increase the likelihood for biological plausibility. ${ }^{47}$ Taking into account the well-known heterogeneous receptor-binding profiles of antipsychotics and their complex dose-response relationships in human subjects the absence of clear demonstration of dose-effect association in our study might represent the final outcome of perplexing action of medications with subtle differences in biological actions. ${ }^{48}$

Our report of the trend of bone mineral depletion is also well coherent with epidemiological evidence linking antipsychotic drug therapy and fracture risk due to either osteoporosis (low bone density) and/or osteomalacia. ${ }^{4-8}$ The results of previous similar studies (about calcemia) which were not fully consistent with ours, had cross-sectional design limiting their capacity for detection of fine oscillations of tightly regulated parameters (like calcium) and also hold many other methodological differences. ${ }^{13-15,29}$ In our study multiple homeostatic pathways were probably affected indicating nonspecific effects which were in agreement with the fact that many drugs decrease calcemia by simultaneous mechanisms influencing at the same time others ions. ${ }^{35,36}$ Our study is unable to answer definitively if antipsychotic drugs or some other source disturb calcemia as it was designed to be confirmatory for the primary research question. Larger sample size and a placebo-controlled group are necessary to increase power for both excluding false-negative results and assessing causality relationships.

In conclusion, antipsychotic drug treatment during the initiation or switching phase was associated with significant fluctuation of parameters of calcium homeostasis in the blood of adults in mature age with a psychotic disorder and several risk factors for bone metabolism disorders, with the general depletion trend. The exact cause, mechanism and true clinical significance of that effect are currently unknown. We recommend further detailed research of the topic, primarily aimed at possible molecular targets playing the role for bone mineral homeostasis and metabolism of calcitropic hormones.

\section{Supplementary Materials}

The online-only Data Supplement is available with this article at http://dx.doi.org/10.4306/pi.2016.13.1.89.

\section{Acknowledgments}

Authors would like to thank Mr Zoran Vuckovic, Mrs Dragana Nedovic and Mrs Sladjana Petrovic for technical assistance during laboratory work and Mrs Nevena Simsic for manuscript editing. Dragan R. Milovanovic and Slobodan M. Jankovic thank to Ministry of Education, Science and Technological Development of Republic of Serbia whose scientific activities are partially supported with the research grant $\mathrm{N}^{\circ} 175007$.

\section{REFERENCES}

1. Johnell O, Kanis JA. An estimate of the worldwide prevalence and disability associated with osteoporotic fractures. Osteoporos Int 2006; 17:1726-1733.

2. Russell LA. Osteoporosis and osteomalacia. Rheum Dis Clin North Am 2010;36:665-680.

3. Fong J, Khan A. Hypocalcemia: updates in diagnosis and management for primary care. Can Fam Physician 2012;58:158-162.

4. Liperoti R, Onder G, Lapane KL, Mor V, Friedman JH, Bernabei R, et al. Conventional or atypical antipsychotics and the risk of femur fracture among elderly patients: results of a case-control study. J Clin Psychiatry 2007;68:929-934.

5. Pouwels S, van Staa TP, Egberts AC, Leufkens HG, Cooper C, de Vries F. Antipsychotic use and the risk of hip/femur fracture: a populationbased case-control study. Osteoporos Int 2009;20:1499-1506.

6. Jalbert JJ, Eaton CB, Miller SC, Lapane KL. Antipsychotic use and the risk of hip fracture among older adults afflicted with dementia. J Am Med Dir Assoc 2010;11:120-127.

7. Lee TY, Chung MY, Chung HK, Choi JH, Kim TY, So HS. Bone density in chronic schizophrenia with long-term antipsychotic treatment: preliminary study. Psychiatry Investig 2010;7:278-284.

8. Roke Y, van Harten PN, Buitelaar JK, Tenback DE, Quekel LG, de Rijke YB, et al. Bone mineral density in male adolescents with autism spectrum disorders and disruptive behavior disorder with or without antipsychotic treatment. Eur J Endocrinol 2012;167:855-863.

9. O'Keane V. Antipsychotic-induced hyperprolactinaemia, hypogonadism and osteoporosis in the treatment of schizophrenia. J Psychopharmacol 2008;22(2 Suppl):70-75.

10. Seriwatanachai D, Thongchote K, Charoenphandhu N, Pandaranandaka J, Tudpor K, Teerapornpuntakit J, et al. Prolactin directly enhances bone turnover by raising osteoblast-expressed receptor activator of nuclear factor kappaB ligand/osteoprotegerin ratio. Bone 2008; 42:535546.

11. Motyl KJ, Dick-de-Paula I, Maloney AE, Lotinun S, Bornstein S, de Paula FJ, et al. Trabecular bone loss after administration of the secondgeneration antipsychotic risperidone is independent of weight gain. Bone 2012;50:490-498.

12. Sugawara N, Yasui-Furukori N, Fujii A, Saito M, Sato Y, Nakagami T, et al. No association between bone mass and prolactin levels among patients with schizophrenia. Hum Psychopharmacol 2011;26:596-601.

13. Baastrup PC, Christiansen C, Transbol I. Calcium metabolism in schizophrenic patients on long-term neuroleptic therapy. Neuropsychobiology 1980;6:56-59.

14. Nechifor M, Vaideanu C, Palamaru I, Borza C, Mindreci I. The influence of some antipsychotics on erythrocyte magnesium and plasma magnesium, calcium, copper and zinc in patients with paranoid schizophrenia. J Am Coll Nutr 2004;23:549S-551S.

15. Wyszogrodzka-Kucharska A, Rabe-Jablonska J. Calcium balance and regulation in schizophrenic patients treated with second generation antipsychotics. Psychiatr Pol 2005;39:1157-1171.

16. Zornic N, Jovanovic Radojevic D, Jankovic S, Djuric D, Varjacic M, Simic VD, et al. Monitoring of drug-associated electrolyte disturbances in a hospital. Pharmacoepidemiol Drug Saf 2009;18:1026-1033.

17. Milovanovic DR, Janjic V, Zornic N, Djukic Dejanovic S, Jankovic SM. Risperidone-associated hypocalcemia. Am J Psychiatry 2010;167: 1533-1534. 
18. Kishimoto T, De Hert M, Carlson HE, Manu P, Correll CU. Osteoporosis and fracture risk in people with schizophrenia. Curr Opin Psychiatry 2012;25:415-429.

19. Douglas IJ, Smeeth L. Exposure to antipsychotics and risk of stroke: self controlled case series study. BMJ 2008;337:a1227.

20. Keks NA, Hope J. Long-term management of people with psychotic disorders in the community. Aust Prescr 2007;30:44-46.

21. Morgan JL, Skulan JL, Gordon GW, Romaniello SJ, Smith SM, Anbar AD. Rapidly assessing changes in bone mineral balance using natural stable calcium isotopes. Proc Natl Acad Sci U S A 2012;109:9989-9994.

22. James MT, Zhang J, Lyon AW, Hemmelgarn BR. Derivation and internal validation of an equation for albumin-adjusted calcium. BMC Clin Pathol 2008;8:12.

23. National Osteoporosis Foundation. Clinician's Guide to Prevention and Treatment of Osteoporosis. Washington DC: National Osteoporosis Foundation; 2010.

24. Taylor D, Paton C, Kapur S. The Maudsley Prescribing Guidelines in Psychiatry. 11th Edition. Chichester: Wiley Blackwell; 2012.

25. Benrimoj SI, Langford JH, Christian J, Charlesworth A, Steans A. Efficacy and tolerability of the anti-inflammatory throat lozenge flurbiprofen $8.75 \mathrm{mg}$ in the treatment of sore throat: a randomised, doubleblind, placebo-controlled study. Clin Drug Invest 2001;21:183-193.

26. Favus MJ. Mineral and Bone Homeostasis. In: Goldman L, Ausiello D, Editors. Cecil Medicine. 23rd Edition. Philadelphia: Saunders Elsevier, 2008, p. 1871-1879.

27. Schoeber JP, Hoenderop JG, Bindels RJ. Concerted action of associated proteins in the regulation of TRPV5 and TRPV6. Biochem Soc Trans 2007;35(Pt 1):115-119.

28. Itzhaky D, Amital D, Gorden K, Bogomolni A, Arnson Y, Amital H. Low serum vitamin $\mathrm{D}$ concentrations in patients with schizophrenia. Isr Med Assoc J 2012;14:88-92.

29. Jamilian H, Bagherzadeh K, Nazeri Z, Hassanijirdehi M. Vitamin D, parathyroid hormone, serum calcium and phosphorus in patients with schizophrenia and major depression. Int J Psychiatry Clin Pract 2013;17:30-34.

30. Skouroliakou M, Giannopoulou I, Maria SG, Kostara C, Koutri K, Kakavelaki C. Vitamin D insufficiency in obese patients with severe mental illness taking olanzapine. Med J Nutrition Metab 2012;5:219-225.

31. Henry HL. Regulation of vitamin D metabolism. Best Pract Res Clin Endocrinol Metab 2011;25:531-541.

32. Daskalopoulos EP, Lang MA, Marselos M, Malliou F, Konstandi M. $\mathrm{D}_{2}$-dopaminergic receptor-linked pathways: critical regulators of $\mathrm{CY}$ P3A, CYP2C, and CYP2D. Mol Pharmacol 2012;82:668-678.

33. Wojcikowski J, Haduch A, Daniel WA. Effect of classic and atypical neuroleptics on cytochrome P450 3A (CYP3A) in rat liver. Pharmacol
Rep 2012;64:1411-1418.

34. Martin A, Quarles LD. Evidence for FGF23 involvement in a bonekidney axis regulating bone mineralization and systemic phosphate and vitamin D homeostasis. Adv Exp Med Biol 2012;728:65-83.

35. Wu J, Carter A. Magnesium: the forgotten electrolyte. Aust Prescr 2007;30:102-105.

36. Liamis G, Milinos HJ, Elisaf M. A review of drug-induced hypocalcemia. J Bone Miner Metab 2009;27:635-642.

37. Liamis G, Milionis HJ, Elisaf M. Medication-induced hypophosphatemia: a review. QJM 2010;103:449-459.

38. Delva NJ, Crammer JL, Jarzylo SV, Lawson JS, Owen JA, Sribney M, et al. Osteopenia, pathological fractures, and increased urinary calcium excretion in schizophrenic patients with polydipsia. Biol Psychiatry 1989;26:781-793.

39. Vetter T, Lohse MJ. Magnesium and the parathyroid. Curr Opin Nephrol Hypertens 2002;11:403-410.

40. Higuchi T, Komoda T, Sugishita M, Yamazaki J, Miura M, Sakagishi Y, et al. Certain neuroleptics reduce bone mineralization in schizophrenic patients. Neuropsychobiology 1987;18:185-188.

41. Sahota O, Mundey MK, San P, Godber IM, Hosking DJ. Vitamin D insufficiency and the blunted PTH response in established osteoporosis: the role of magnesium deficiency. Osteoporos Int 2006;17:1013-1021.

42. Huang C, Miller RT. Regulation of renal ion transport by the calciumsensing receptor: an update. Curr Opin Nephrol Hypertens 2007;16: 437-443.

43. Wu-Wong JR, Nakane M, Chen YW, Mizobuchi M. Mechanistic analysis for time-dependent effects of cinacalcet on serum calcium, phosphorus, and parathyroid hormone levels in 5/6 nephrectomized rats. Physiol Rep 2013;1:e00046.

44. Doknic M, Maric NP, Britvic D, Pekic S, Damjanovic A, Miljic D, et al. Bone remodeling, bone mass and weight gain in patients with stabilized schizophrenia in real-life conditions treated with long-acting injectable risperidone. Neuroendocrinology 2011;94:246-254.

45. Labad J, Stojanovic-Perez A, Montalvo I, Sole M, Cabezas A, Ortega L, et al. Stress biomarkers as predictors of transition to psychosis in atrisk mental states: roles for cortisol, prolactin and albumin. J Psychiatr Res 2015;60:163-169.

46. Vlahovic Z, Radojkovic D. Healthcare in Serbia in transition period. EPMA J 2010;1:601-606.

47. Tugwell P, Haynes B. Assessing Claims of Causation. In: Haynes RB, Sackett DL, Guyatt GH, Tugwell P, Editors. Clinical Epidemiology How to Do Clinical Practice Research. 3rd Edition. Philadelphia: Lippincot Williams \& Wilkins, 2006, p. 356-387.

48. Davis JM, Chen N. Dose response and dose equivalence of antipsychotics. J Clin Psychopharmacol 2004;24:192-208. 